\title{
Comportamento da precipitação como fator ativo de processos erosivos no município de Rondon do Pará, PA (Brasil)
}

Behavior of precipitation as an active factor of erosive processes in municipality of Rondon do Pará, PA (Brazil)

\author{
A. G. Rosa ${ }^{1 *}$;. T. S. Dos Santos ${ }^{1}$; J. A. Da Costa루 D. D. F. Fonseca ${ }^{3}$; A. M. L. De \\ Sousa $^{4}$ \\ ${ }^{1}$ Programa de Pós-Graduação de Ciências Ambientais, Universidade Federal do Pará, 66075-110, Belém-Pará, Brasil \\ ${ }^{2}$ Instituto Ciberespacial - ICIBE, Universidade Federal Rural da Amazônia, 66.077-83, Belém-Pará, Brasil \\ ${ }^{3}$ Superintendência Belém - SUREG/BE, Serviço Geológico do Brasil-CPRM, 66.095-110, Belém-Pará, Brasil \\ ${ }^{4}$ Instituto Sócio Ambiental - ISARH, Universidade Federal Rural da Amazônia, 66.077-83, Belém-Pará, Brasil \\ *amandagamarosa@gmail.com
}

(Recebido em 21 de novembro de 2016; aceito em 10 de janeiro de 2017)

\begin{abstract}
Buscando contribuir com informações acerca do comportamento da precipitação e as perdas de solo em Rondon do Pará/PA, este trabalho buscou estimar a precipitação do município, entre os anos de 1999 e 2015, gerar uma normal provisória da precipitação e avaliar o comportamento desta nos casos de erosão registrados na região. Para isto, foram utilizados dados diários de precipitação obtidos a partir dos satélites CMORPH nos anos de 1999 a 2015, provenientes de um quadrante do município. De posse destes, foram gerados a normal provisória e o balanço hidrológico de Rondon do Pará. Dados de ocorrências de erosão da Defesa Civil foram obtidos para, junto aos de precipitação, serem analisados individualmente. A normal provisória apresentou ano hidrológico iniciando em outubro com a estação chuvosa e finalizando em setembro com o fim da estiagem, sendo o mês de março o mais chuvoso e agosto o menos chuvoso. $\mathrm{O}$ balanço hidrológico exibiu excedente hídrico nos meses de janeiro a abril e deficiência hídrica de junho a novembro, havendo reposição a partir de dezembro com a retomada das chuvas. Os casos de erosão apresentaram distribuição anual semelhante à distribuição da precipitação, indicando sua grande influência sobre os mesmos. A análise individual dos casos mostrou que a erosão pode ser decorrente tanto de precipitação ocorrida no dia do evento como acumulada nos cinco dias antecedentes ao evento, sendo este último caso o mais comum. Essas informações são úteis para o planejamento do município, nas áreas urbana e rural.
\end{abstract}

Palavras-chave: comportamento da chuva, erosão, planejamento.

Seeking to contribute with information about the behavior of precipitation and soil losses in Rondon do Pará/PA, this study sought to estimate the precipitation of city between the years 1999 and 2015, to generate a Provisional Normal of precipitation and to evaluate the behavior of that on cases of erosion recorded in the region. For this, was used daily precipitation data from satellites CMORPH in the years 1999-2015, from one quadrant of the city. In possession of these, were generated provisional normal and the hydrological balance of Rondon do Pará. The erosion occurrence data of Civil Defense were obtained for, with the precipitation data, are examined individually. The Provisional Normal presented hydrological year starting in October with the rainy season and ending in September with the end of the dry season, being the month of March the wettest and August the less rainy. The hydrological balance showed surplus water in the months from January to April and water deficiency from June to November, with replacement from December with the return of the rains. The cases of erosion presented annual distribution similar to the distribution of precipitation, indicating its great influence on them. Individual analysis of cases showed that erosion may be due as much precipitation occurred on the day of the event as accumulated in the five days prior to the event, the latter being the most common case. This information comes useful for municipal planning, in urban and rural areas.

Keywords: behavior of rain, erosion, planning. 


\section{INTRODUÇÃO}

Integrante da dinâmica superficial da terra, a erosão constitui-se como o principal modelador fisiográfico do planeta. Consiste em um processo que ocorre naturalmente envolvendo as seguintes etapas: remoção de partículas, transporte e deposição lenta ou acelerada dos materiais, sejam eles formados por rochas, solos ou depósitos superficiais não consolidados [1,2].

Quanto à sua classificação em função dos seus fatores ativos (condicionantes), as erosões podem ser divididas em 15 tipos, conforme foi proposto por Zachar em 1982 [3], porém, em síntese, o mais comum hoje é classificá-las em quatro grandes grupos: erosão eólica, erosão glacial, erosão hídrica e erosão organogênica [4]. A erosão hídrica, tipo mais comum em regiões tropicais, ocorre a partir da desagregação das partículas de solo como consequência do impacto direto das gotas de chuva, do escoamento superficial, da drenagem dos rios ou também da ação do mar. Após essa desagregação, parte significativa das partículas é transportada, removendo certa quantidade de solo [5].

A chuva é um dos principais agentes responsáveis pela energia necessária para a ocorrência da erosão, tanto pelo impacto direto sobre a superfície do solo quanto pela sua capacidade de produzir escoamento superficial [6]. Quanto mais intensa ela for, menos tempo e capacidade os solos terão para a água infiltre, favorecendo o aumento do escoamento na superfície e, consequentemente, o aumento das chances de ocorrência de erosão laminar, podendo evoluir para sulcos, ravinas e até voçorocas. A quantidade de chuva também é importante, porque uma chuva pode ser de intensidade relativamente baixa, porém pode durar um período muito longo, tornando os solos saturados e suscetíveis à erosão [2].

Nesse contexto, a busca por maiores conhecimentos e informações acerca da precipitação e suas influências no desencadeamento de processos erosivos se torna essencial, principalmente quando se diz respeito aos riscos nas áreas urbanas, cuja análise é impulsionada pela necessidade de identificar situações de risco e realizar o planejamento adequado.

Diversos trabalhos têm sido realizados abordando a resistência de solos, em distintas situações, à ação das águas, como o de Corrêa et al. (2010) [7] em estradas em Itaiópolis (SC); Santos et al. (2002) [8] em vertentes de encostas em Ouro Preto (MG); Prieto (2010) [9] em um loteamento em Ponta Grossa (PR) e Alves (2007) [10] em zona rural de Uberlândia (MG), entre outros. Todos estes autores chamam a atenção para a necessidade de planejamento e de prevenção de situações de risco, a fim de evitar danos tanto ambientais como sociais e econômicos.

Diante disso, este trabalho objetivou estimar a precipitação do município de Rondon do Pará (PA), entre os anos 1999 e 2015, tendo em vista a carência deste tipo de dados para o local e o destaque que este município tem recebido nos últimos anos devido à ocorrência de erosões em sua área urbana, afetando centenas de pessoas. Além disto, buscou-se avaliar os casos de erosão identificados pela Defesa Civil do Pará em Rondon do Pará com base no comportamento da precipitação no dia do evento erosivo e nos dias que antecederam o evento.

\section{MATERIAL E MÉTODOS}

A área de estudo compreende a área urbana do município de Rondon do Pará/PA, localizado na mesorregião do sudeste paraense e na microrregião de Paragominas (Figura 1). O município em questão possui extensão territorial de $8.296,394 \mathrm{~km}^{2}$ e sua área urbana possui de cerca 9,54 $\mathrm{km}^{2}$, tendo sua sede municipal nas coordenadas geográficas $4^{\circ} 46^{\prime} 34^{\prime \prime} \mathrm{S}$ e $48^{\circ} 04^{\prime} 02^{\prime \prime} \mathrm{O}$.

O tipo climático predominante na região é Aw, de acordo com critérios de Koppen, caracterizado por um clima tropical chuvoso. $\mathrm{O}$ ano hidrológico da região começa em outubro com a estação chuvosa e termina em setembro, com o fim da estiagem [11].

Os principais sistemas que influenciam no tempo e clima da Região Norte do Brasil, onde está incluída a área de estudo, são a ZCIT (Zona de Convergência Intertropical), as Linhas de Instabilidade (LIs) e circulação de brisa marítima, a penetração de sistemas frontais, o deslocamento da ASAS/ASAN (Alta Subtropical do Atlântico Sul/ Alta Subtropical do Atlântico Norte) e da Alta da Bolívia, a qual pode interagir com Distúrbios Ondulatórios de Leste e outros mecanismos de escala regional e global (El Niño Oscilação Sul e dipolo do Atlântico Tropical, por exemplo) [5]. 


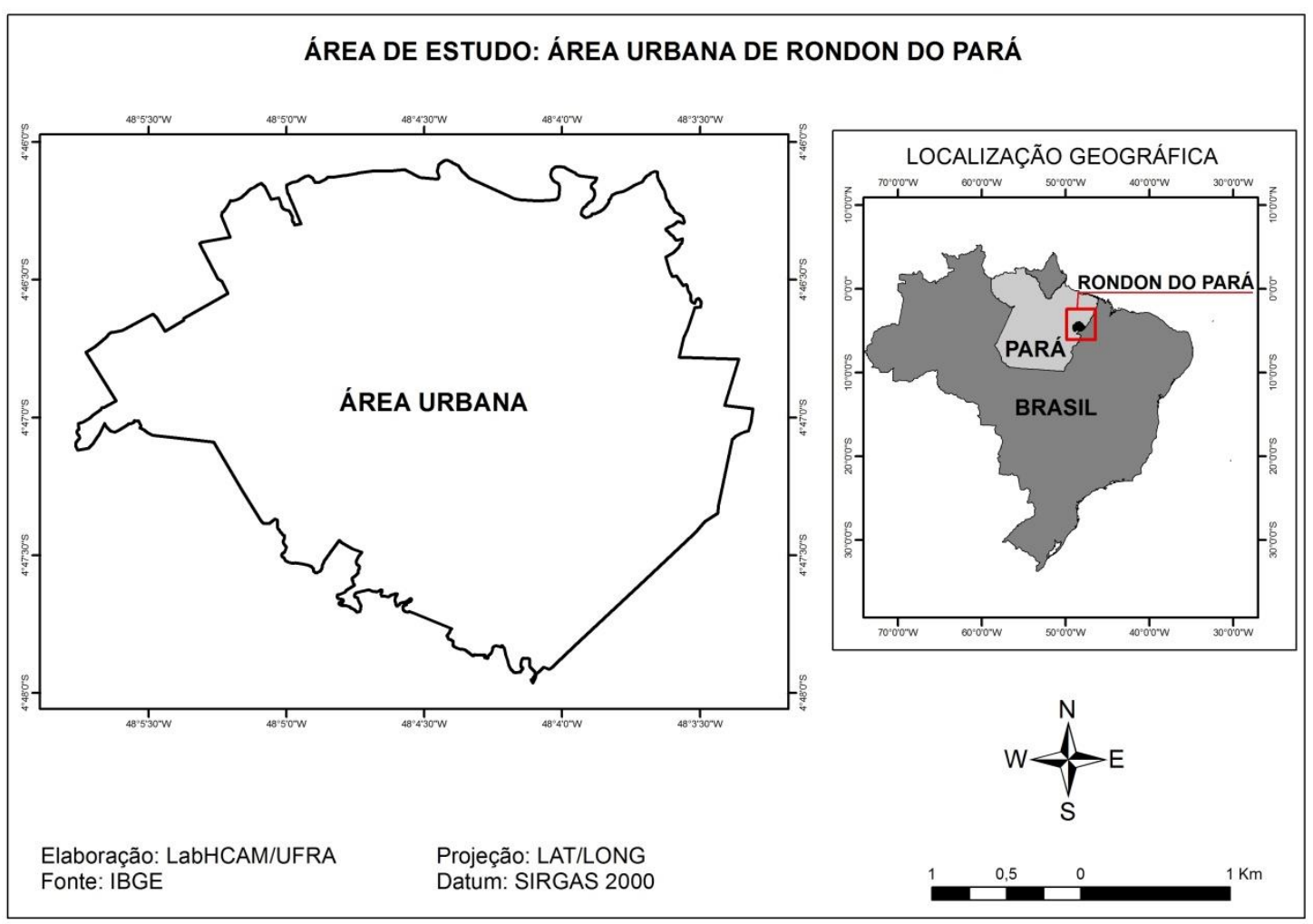

Figura 1: Localização da área de estudo no estado do Pará. Fonte: Autores.

Os processos erosivos, naturais de evolução geomorfológica na região, que está localizada no Domínio de Colinas Dissecadas e Morros Baixos e possui relevo de baixo platô, com amplitude média de 95 metros e bordas relativamente íngremes, e solos muito profundos, friáveis e com alta erodibilidade (latossolo amarelo), se intensificam entre novembro e maio, período de grande precipitação na região, influenciados também pela concentração de águas pluviais em galerias subterrâneas que deságuam em poucos pontos na cidade [11].

$\mathrm{Na}$ metodologia foram utilizados dados diários de precipitação obtidos a partir dos satélites CMORPH (Climate Prediction Center morphing method), para determinação da normal provisória do município e para a avaliação do comportamento da precipitação. Os dados de chuva do CMORPH (disponíveis em ftp.cpc.ncep.noaa.gov/), com séries a partir de 1998, além de fornecer dados espaciais satisfatórios com resolução espacial de $64 \mathrm{~km}^{2}$, apresenta bastante confiabilidade quantitativa, como foi evidenciado em diversos estudos [12, 13]. Neste trabalho foram utilizados dados entre os anos de 1999 e 2015 provenientes de um quadrante do município, que inclui a área urbana, entre as latitudes $4^{\circ} \mathrm{S}$ e $5^{\circ} \mathrm{S}$ e entre as longitudes $48^{\circ} \mathrm{W}$ e $49^{\circ} \mathrm{W}$. Para esta tarefa obteve-se o auxílio do software GrADS 2.0.

Embora seja necessária uma série de dados de precipitação de no mínimo 30 anos para a definição da normal climatológica padronizada de uma região [14], foi usada uma série de 17 anos em função da quantidade limitada de dados CMORPH e da indisponibilidade de dados de precipitação em outros bancos de dados, gerando uma Normal Provisória para o município. As Normais Provisórias são médias de curto prazo, segundo a OMM (1989) [14], calculadas, em substituição às Normais Climatológicas, em casos de insuficiência de dados, baseadas em observações que se estendam sobre um período mínimo de 10 anos.

Além da definição da normal provisória, foi elaborado o balanço hidrológico do município, a partir da metodologia desenvolvida por Thornthwaite e Mather (1955) [15]. Com a realização do balanço hidrológico foi possível avaliar a entrada, saída e armazenamento de água no solo ao longo do ano, o que pode explicar a distribuição da ocorrência dos eventos erosivos. Para a elaboração deste balanço foi definida uma capacidade de campo de $100 \mathrm{~mm}$ e foram usados os dados de precipitação CMORPH de 1999 a 2015 de Rondon do Pará (PA) e os dados de temperatura oriundos da estação meteorológica do Instituto Nacional de Meteorologia - INMET 
localizada no município de Marabá (PA) (distante $135 \mathrm{~km}$ da área de estudo), a partir de sua normal climatológica de 1961-1990. Foram utilizados dados de Marabá devido ao fato de que este é o município mais próximo da área de estudo que possui dados climatológicos por um longo período e ao fato de que a estação meteorológica de Rondon do Pará possui dados apenas a partir de 2008 e estes se mostraram insatisfatórios para este estudo.

Os dados de eventos de erosão foram provenientes do banco de dados da Defesa Civil do Estado do Pará entre os anos de 1999 e 2015 [16]. Os eventos foram analisados individualmente e relacionados com o comportamento da distribuição da precipitação na região, buscando identificar os tipos de comportamentos pluviométricos que podem influenciar no desencadeamento de eventos erosivos em certo espaço de tempo.

Foram adotados como evento de erosão outros tipos de desastres naturais identificados pela Defesa Civil que tenham relação com este, seja como causa ou consequência, tendo em vista que a interpretação destes eventos pelos funcionários da Defesa Civil, ao longo dos 17 anos de dados, pode ser falha ou conflitante. Dessa forma, eventos como Enxurrada e Deslizamento também foram considerados eventos de erosão.

Para a análise temporal da precipitação foi definido um período de observação de 6 dias, sendo o dia do evento identificado e os 5 dias que antecederam o evento erosivo, julgando que um processo de erosão pode ser influenciado, além dos fatores intrínsecos e extrínsecos do ambiente, por precipitações ocorridas no dia do evento e acumuladas nos 5 dias anteriores ao evento, ou seja, pode ser influenciado tanto pela intensidade quanto pela quantidade e distribuição de precipitação. Este período de análise foi definido a partir de sugestões de Castro et al. (2012) [17], os quais afirmaram que a observação das precipitações ocorridas nos cinco dias antes da erosão é a mais adequada para explicá-la.

\section{RESULTADOS E DISCUSSÃO}

\section{Normal Provisória de Rondon do Pará (PA)}

Os dados diários de precipitação obtidos a partir dos satélites CMORPH foram acumulados mensalmente gerando uma normal provisória conforme é apresentado abaixo (Figura 2), com o ano hidrológico iniciando em outubro com o início da estação chuvosa e finalizando em setembro com o fim da estiagem. O mês mais chuvoso é o mês de março e o menos chuvoso é o mês de agosto, apresentando semelhanças com o comportamento anual da precipitação em regiões próximas, como no município de Marabá, o mais próximo de Rondon do Pará com Normal Climatológica definida, que também tem como o mês mais chuvoso o mês de março e como o menos chuvoso o mês de agosto [18].

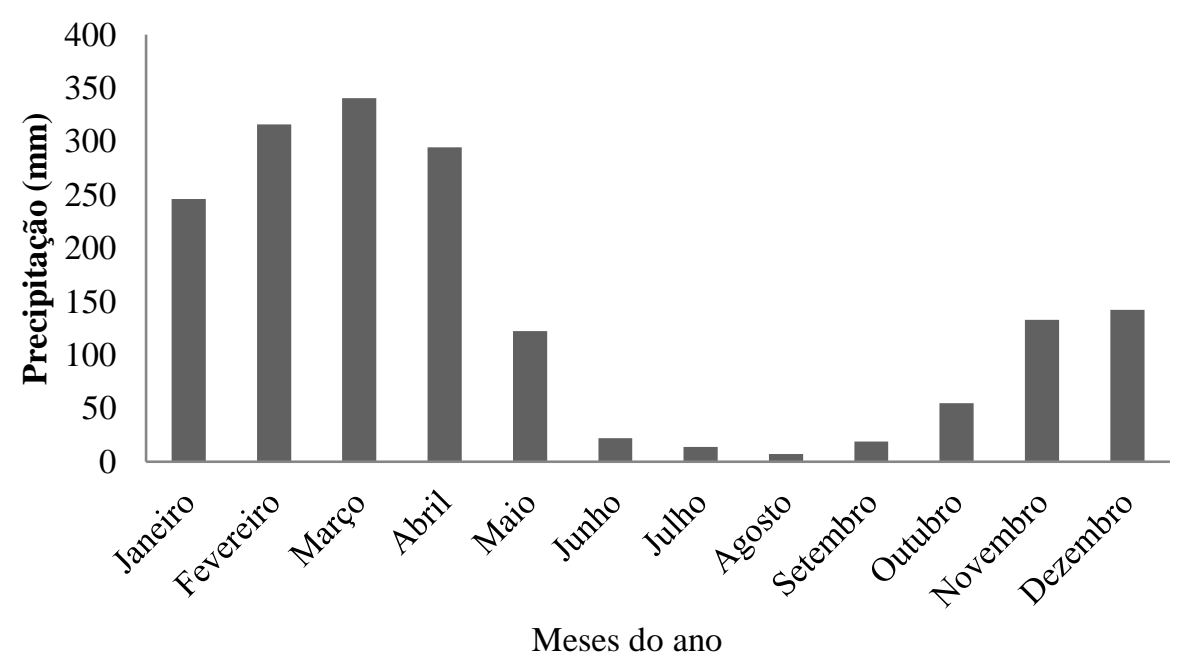

Figura 2: Normal Provisória do município de Rondon do Pará (PA), com base nos anos 1999 a 2015. 
Para a série de dados investigada, a média pluviométrica anual encontrada foi de $1.710 \mathrm{~mm}$, variando entre $1.261 \mathrm{~mm}$ a $2.504 \mathrm{~mm}$. A região de Rondon do Pará possui alta pluviosidade, concentrada principalmente entre os meses de fevereiro a abril, correspondendo a 72,04\% da precipitação anual.

A precipitação e os eventos erosivos entre 1999 e 2015

Segundo Defesa Civil [16], foram registrados oficialmente 11 casos de processos erosivos de 1999 a 2015 no município (Tabela 1), com 730 pessoas afetadas. No entanto esses valores tendem a ser superiores na realidade, tendo em vista a deficiência na obtenção e armazenamento de dados nos anos iniciais das medições e a insuficiência de ações governamentais nos atendimentos a desastres, em função da grande extensão territorial do estado e das dificuldades institucionais.

Os casos registrados tiveram distribuição anual semelhante ao comportamento anual da precipitação, o que era esperado, pois a precipitação é um dos principais fatores ativos da erosão, embora não seja o único. Na Figura 3 pode-se observar, como dito, que, normalmente, os meses de maior precipitação, de outubro a maio, apresentam maior frequência de processos erosivos no município de Rondon do Pará, sendo o mês de fevereiro o mais crítico.

Tabela 1: Eventos erosivos identificados pela Defesa Civil do Estado do Pará entre os anos 1999 e 2015.

\begin{tabular}{cc}
\hline Data do Evento & População Afetada $\left(\mathbf{n}^{\circ}\right.$ pessoas $)$ \\
\hline $\mathbf{0 8 / 0 3 / 1 9 9 9}$ & 0 \\
$\mathbf{1 9 / 0 4 / 2 0 0 0}$ & 0 \\
$\mathbf{1 5 / 0 2 / 2 0 0 1}$ & 0 \\
$\mathbf{1 5 / 0 2 / 2 0 0 2}$ & 0 \\
$\mathbf{2 1 / 0 1 / 2 0 0 5}$ & 0 \\
$\mathbf{2 2 / 0 2 / 2 0 0 5}$ & 6 \\
$\mathbf{1 5 / 0 2 / 2 0 0 6}$ & 0 \\
$\mathbf{3 0 / 0 4 / 2 0 0 7}$ & 684 \\
$\mathbf{1 1 / 0 5 / 2 0 0 9}$ & 0 \\
$\mathbf{1 7 / 1 1 / 2 0 1 4}$ & 5 \\
$\mathbf{0 5 / 0 1 / 2 0 1 5}$ & 35 \\
\hline
\end{tabular}

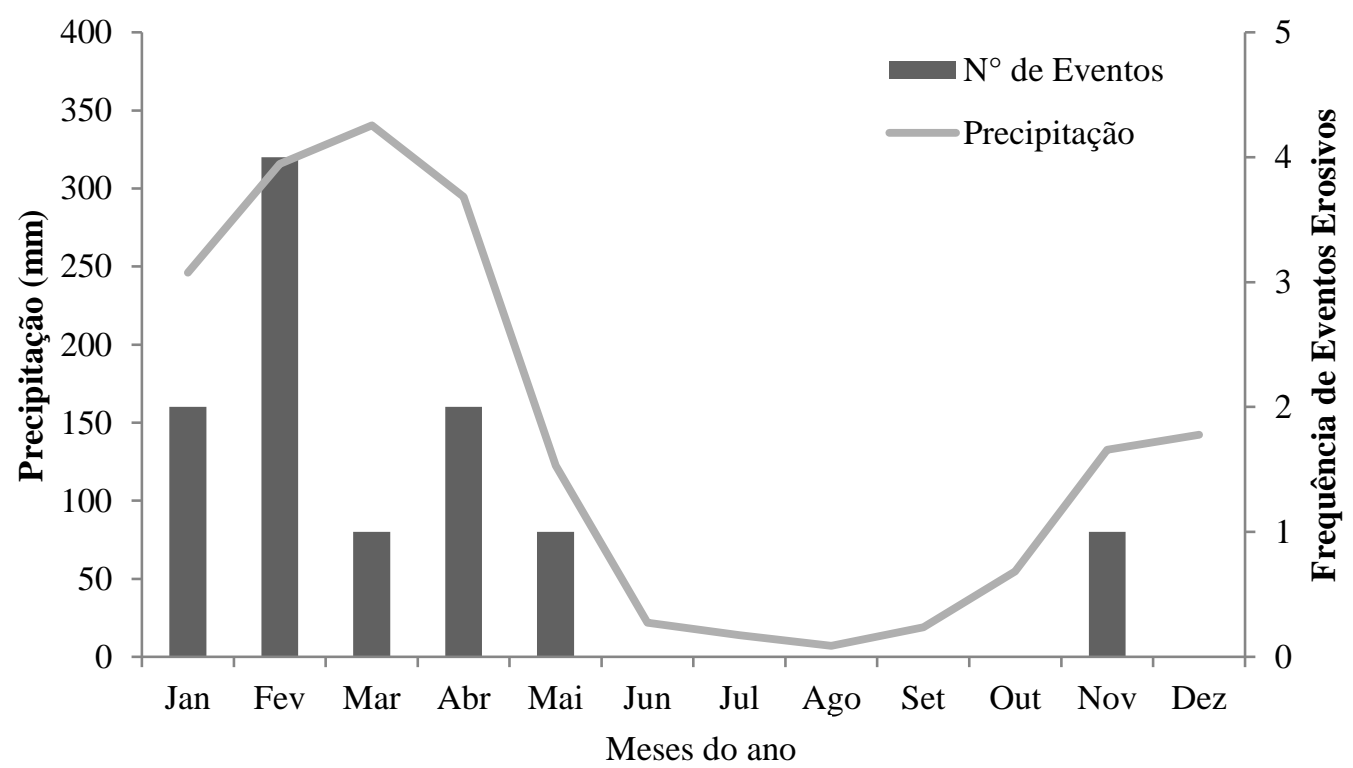

Figura 3: Distribuição e frequência de eventos erosivos e distribuição da precipitação em Rondon do Pará (PA) entre 1999 e 2015. 
A precipitação, na maioria das vezes, pode explicar a ocorrência de um evento erosivo, mas isto não é uma regra, visto que a precipitação é apenas um dos vários fatores influentes. Dentre estes fatores, há a geologia e pedologia da região, a declividade do terreno, o uso e ocupação da terra, entre outros fatores ambientais extrínsecos. Por exemplo, analisando em uma escala de longo período de dados, como é o caso da análise entre 1999 e 2015 (Figura 3), vemos que apesar de o mês de março ser o mais chuvoso, não necessariamente neste mês irão ocorrer mais eventos de erosão, conforme foi registrado pela Defesa Civil.

Embora a erosão não seja totalmente explicada pela precipitação, de todo modo, é esperado que eventos erosivos concentrem suas ocorrências em períodos mais chuvosos do ano. Este tipo de informação é muito útil para o planejamento de um município, onde tomadores de decisão terão conhecimento sobre em quais meses do ano são esperadas as maiores perdas de solo, podendo, assim, selecionar as melhores opções de planejamento urbano e rural.

Nas Figuras 4 e 5 são apresentados os resultados do balanço hidrológico realizado para Rondon do Pará. Com base nelas, podemos observar que entre os meses de janeiro e abril houve um excedente hídrico, ou seja, houve uma sobra de água no período chuvoso, que o solo não teve a capacidade de infiltrar e armazenar. Esta quantidade de água que sobra, normalmente é direcionada ao escoamento superficial, favorecendo a ocorrência de erosões nesse período, tendo em vista que o solo ultrapassou seu limite de armazenamento.

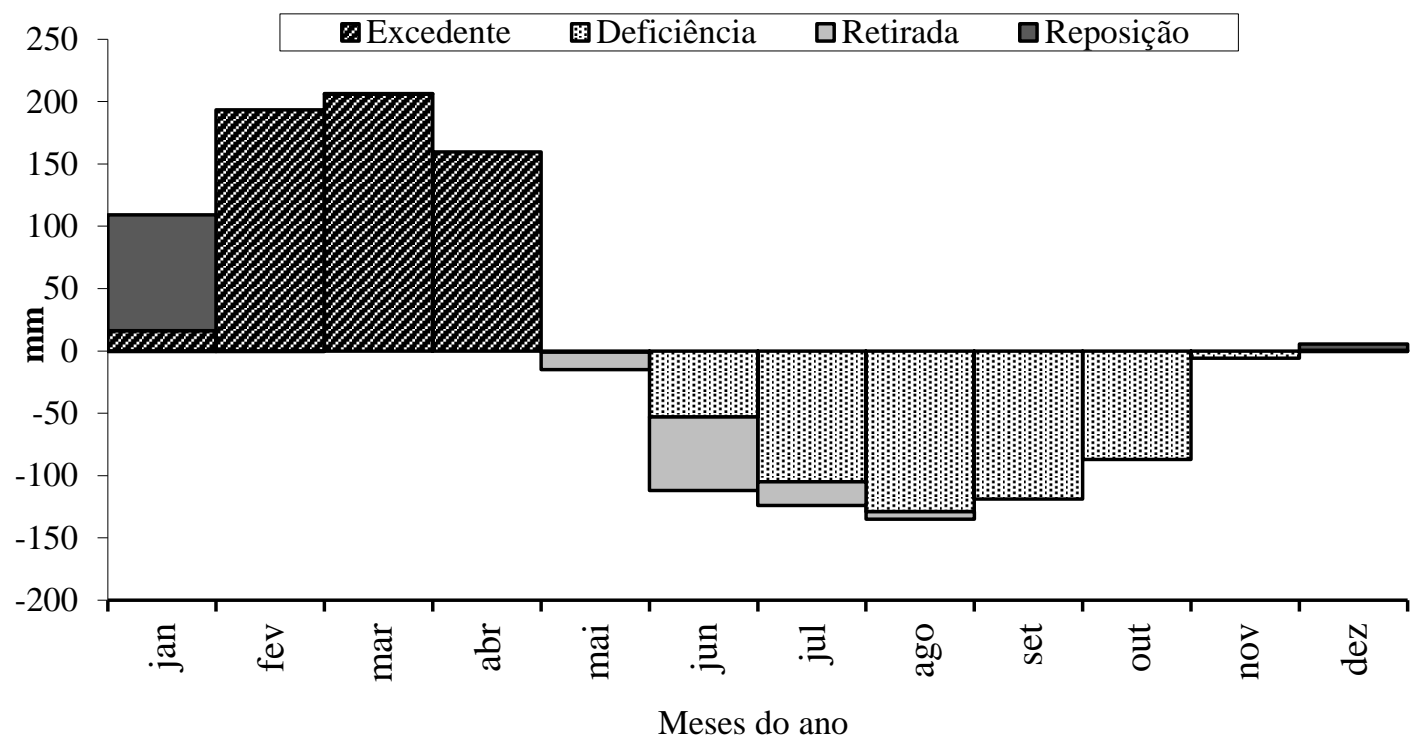

Figura 4: Extrato do Balanço Hidrológico de Rondon do Pará (PA) para o período de 1999 a 2015 s.

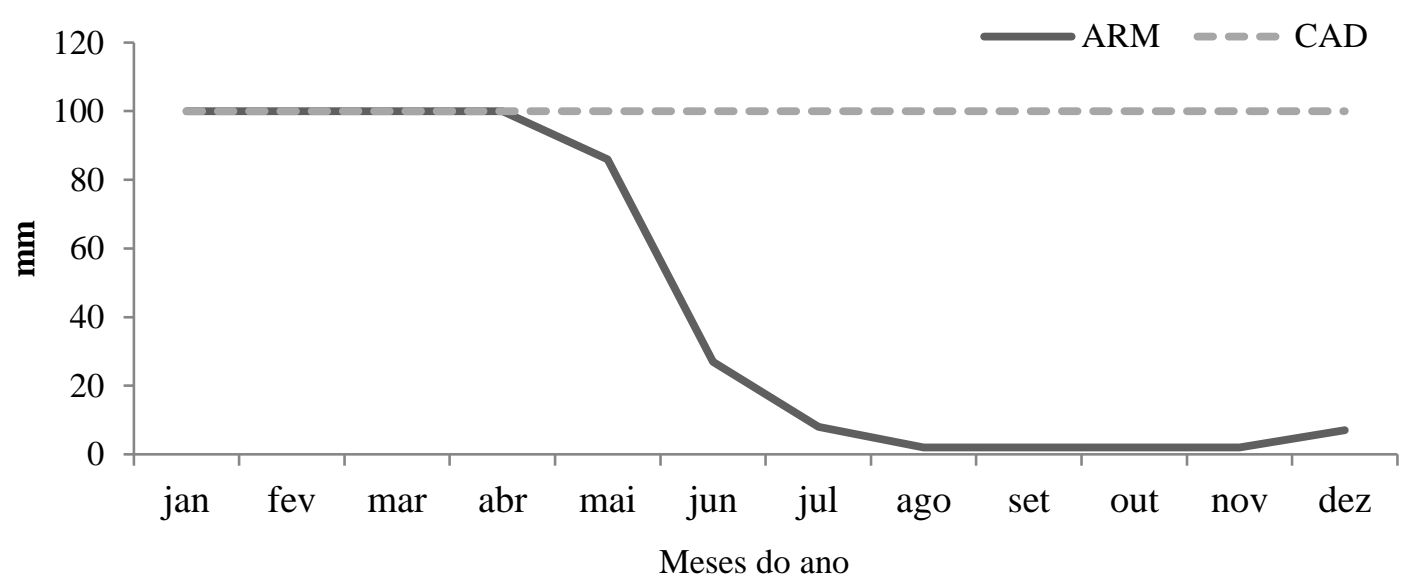

Figura 5: Capacidade de Água Disponível (CAD) e Armazenamento (ARM) de água no solo durante o ano em Rondon do Pará, com base nos anos de 1999 a 2015. 
Com a redução da precipitação a partir do mês de maio passou-se a observar a deficiência hídrica, que é a falta de água no solo, com a consequente retirada de água do solo pela evapotranspiração e a redução do armazenamento. Essa situação se estende até o mês de dezembro, quando recomeça a reposição de água no solo com o retorno da precipitação em outubro. Este período, de maio a novembro, é menos favorável para eventos de erosão.

De dezembro a janeiro ocorre a reposição de água no solo. Logo em janeiro toda a falta de água no solo é suprida e já se tem excedente hídrico, recomeçando o ciclo anual.

\section{Estudo de Caso dos eventos erosivos ocorridos em Rondon do Pará (PA)}

Analisando individualmente os casos de erosão registrados pela Defesa Civil do Pará, verificou-se que um evento erosivo pode ser resposta tanto da precipitação ocorrida no dia do evento como da precipitação acumulada em dias anteriores ao evento, indicando que não apenas a intensidade da chuva, mas também a sua quantidade e distribuição, podem explicar a ocorrência de determinados processos erosivos.

Isto é explicado da seguinte forma: no primeiro caso tem-se uma chuva de alta intensidade ocorrida em um espaço de tempo relativamente curto, um dia, e, dessa forma, os solos terão menos tempo para infiltrar a água, reduzindo sua capacidade retenção, e esta passará a escoar superficialmente, gerando maior energia para a desagregação e transporte de materiais, favorecendo a erosão; no segundo caso se teria uma chuva de intensidade relativamente baixa, mas que ocorreram por um maior tempo, dias seguidos, deixando o solo saturado e, consequentemente, mais suscetível à erosão.

Trabalhos como os de Tatizana et al. (1987) [19] e Castro et al. (2012) [17] também trataram da influência não apenas da precipitação no dia do evento, mas principalmente da precipitação acumulada nos dias anteriores ao evento. Tatizana et al. (1987) [19] trabalhou com a precipitação acumulada de quatro dias para explicar os processos erosivos. Já Castro et al. (2012) [17] definiu que cinco dias de precipitação acumulada seria mais adequado.

Para Delmonaco et al. (1995) [20], os movimentos de massa mais profundos estão mais possivelmente relacionados a chuvas antecedentes acumuladas de vários dias, enquanto que movimentos de massas superficiais estão mais ligados e dependentes da intensidade da chuva em períodos mais curtos. Porém, essas análises não foram possíveis neste trabalho devido à falta de informações sobre as características estruturais das erosões registradas.

O comportamento da precipitação em todos os casos registrados oficialmente pela Defesa Civil, tanto no dia do evento como nos cinco dias que o antecederam (Figura 6). Observam-se dois comportamentos da precipitação como fator ativo no desenvolvimento de processos erosivos: intensa no dia do evento e em quantidade, acumulada do dia do evento e dos cinco dias que o antecederam. A maioria das erosões verificadas é resultante de precipitações acumuladas nos cinco dias antes do evento (nove dos onze casos). Em apenas dois casos, os eventos de 22/02/2005 e 17/11/2014, apresentaram no dia do evento uma precipitação maior que a soma das precipitações dos cinco dias antecedentes.

A média de quantidade de água precipitada que resulta em erosões, acumulando os seis dias de análise, com base do período de dados, é de $152,9 \mathrm{~mm}$, porém variam os eventos que careceram de pouca água para desencadear, como o caso de 30/04/2007 (32 mm), e os que desencadearam após precipitações com grande volume de água, como o caso de 15/02/2006 (388 $\mathrm{mm})$.

Os casos em que houve um acúmulo de água relativamente baixo, e principalmente distribuído por um longo período, a erosão tende a ser explicada especialmente pelos outros fatores influentes, não em maior parte pela ação das chuvas, destacando a grande importância que os outros fatores também têm sobre os processos erosivos. Em casos contrários, podemos ter a chuva como principal fator ativo de erosões.

Dentre os casos de erosões que desencadearam após a precipitação de grande volume de água, destaca-se o ocorrido no dia 15/02/2006, com quantidade total de $388 \mathrm{~mm}$ de água acumulada nos cinco dias que antecederam o evento, sendo os dois dias antecedentes os mais expressivos, um com $182 \mathrm{~mm}$ (13/02/2006) e outro com $180 \mathrm{~mm}$ (14/02/2006). Essa situação não é comum de ocorrer, visto o enorme volume de água em pouco tempo de incidência, com grande 
potencial de causar danos, sendo considerada, desse modo, como um evento extremo. Pesquisas nas mídias e jornais foram realizadas buscando ocorrências de desastres naturais na região nesse período, porém nenhum fato foi encontrado, apenas a ocorrência registrada pela Defesa Civil.
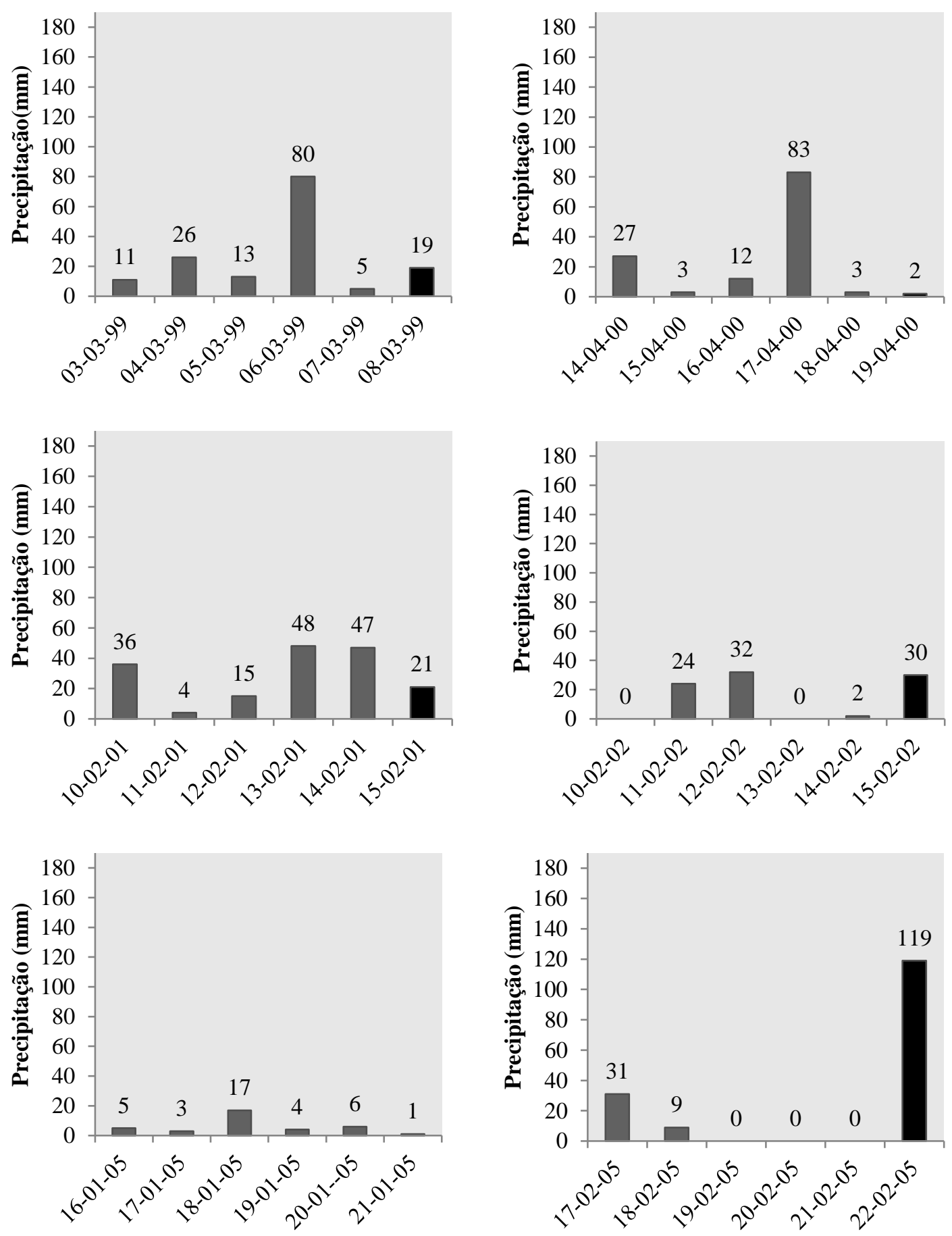

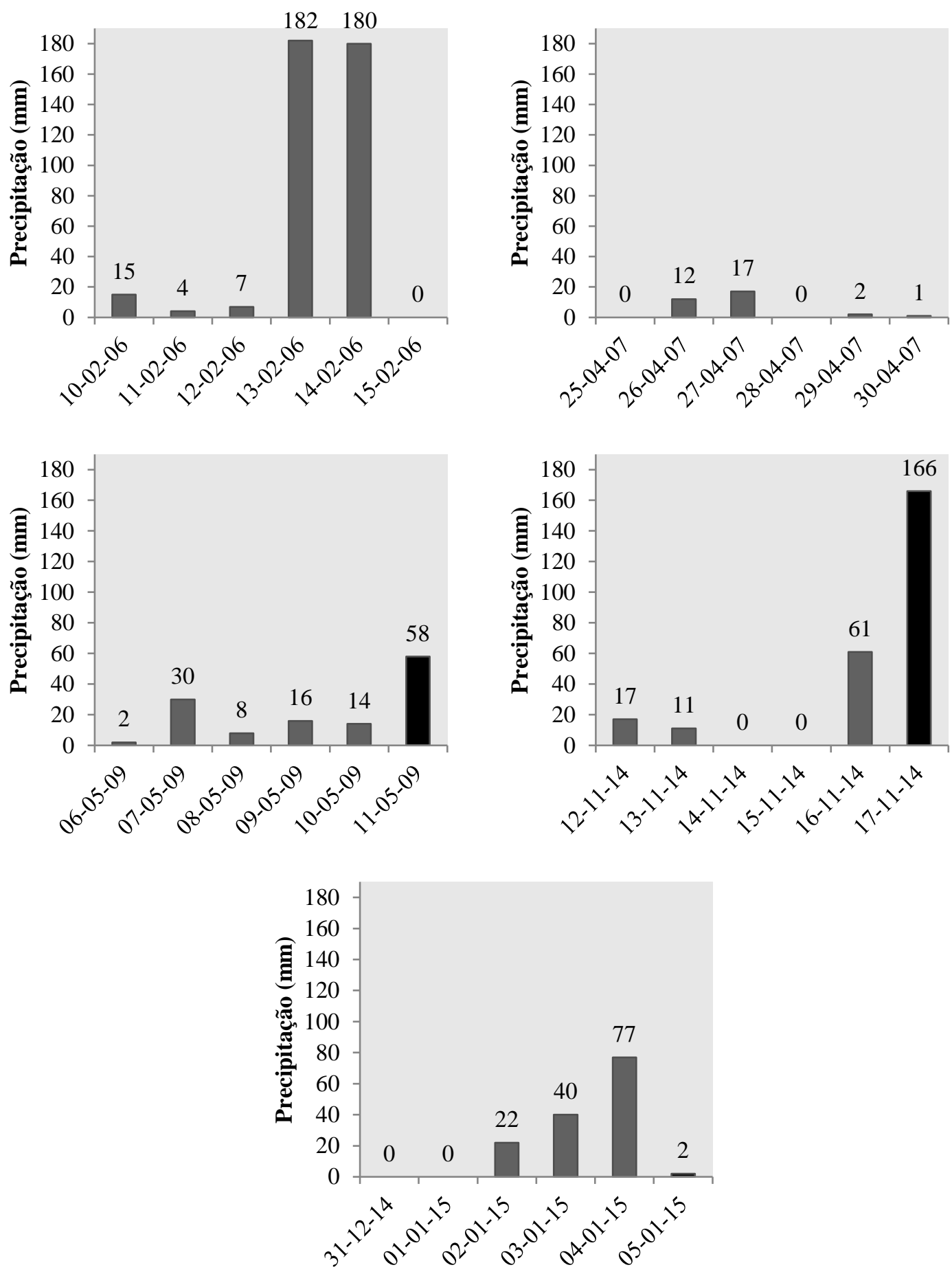

Figura 6: Comportamento da precipitação no dia do evento erosivo e nos cinco dias que o antecederam. Cada gráfico representa um dos eventos erosivos, em ordem cronológica. Observação: O dia do evento é sempre o último dia apresentado no gráfico, representado pela coluna de cor preta.

\section{CONCLUSÃO}

$\mathrm{Na}$ área urbana de Rondon do Pará, os prejuízos decorrentes dos processos erosivos são cada vez mais frequentes e intensos. A precipitação é um fator que traz grande influência sobre estes processos e este trabalho vem apresentar casos que podem comprovar essa afirmação. De acordo com as análises realizadas, observou-se que os eventos registrados oficialmente pela Defesa Civil do Estado do Pará se distribuíram ao longo do ano com comportamento semelhante à distribuição 
da precipitação, sendo os meses de novembro a maio os mais expressivos para as duas variáveis. Nos meses de janeiro a abril, onde se concentram a maior parte das ocorrências de erosão, houve excedente hídrico, ou seja, houve uma sobra de água no solo, onde o mesmo perde a capacidade de infiltrar água e esta se transforma em escoamento superficial, fator que favorece processos erosivos. Assim, concluiu-se que, apesar da precipitação não ser o único fator que influencia no desencadeamento de erosões, ela é um dos fatores ativos de maior importância.

Concluiu-se através das análises individuais dos 11 casos de erosão registrados, que um processo erosivo pode ser explicado, dentre outros fatores, por precipitações ocorridas tanto no dia do evento como nos cinco dias que o antecedem, sendo a maior parte dos eventos resultante de acúmulo de precipitação nos dias que o antecedem. Dentre as situações analisadas, variaram casos de erosão que careceram de pouca quantidade de água para desencadear $(32 \mathrm{~mm} \mathrm{em}$ $30 / 04 / 2007$ ) e casos que careceram de grandes quantidades (388 mm em 15/02/2006).

\section{AGRADECIMENTOS}

Ao Instituto Nacional de Meteorologia - INMET pela disponibilização dos dados meteorológicos.

\section{REFERÊNCIAS BIBLIOGRÁFICAS}

1. Bertoni J, Lombardi Neto F. Conservação do solo. São Paulo: Ícone Editora; 1990. 355 p.

2. Bonna JL. Mapeamento Pedológico e de Suscetibilidade Erosiva no Alto Córrego Prata (Ouro PretoMG) [dissertação]. Belo Horizonte (MG): Universidade Federal de Minas Gerais; 2011. 119 p.

3. Zacar D. Soil erosion. Development in Soil Science, 10. Amsterdam: Elsevier Scientific; 1982.

4. Carvalho JC, Sales MM, Sousa NM, Melo MTS. Processos Erosivos no Centro-Oeste Brasileiro. Brasília: Universidade de Brasília: FINATEC; 2006. 464 p.

5. CEPED - Centro Universitário de Estudos e Pesquisas sobre Desastres. Universidade Federal de Santa Catarina. Atlas brasileiro de desastres naturais: 1991-2012. Volume Pará. 2 ed. rev. ampl. Florianópolis: CEPED UFSC, 114 p., 2013.

6. Pruski FF. Fatores que Interferem na Erosão Hídrica do Solo. In: Pruski FF. (edit.). Conservação de solo e água: Práticas mecânicas para o controle da erosão hídrica. Ed. 2. Viçosa: Ed. UFV; 2009 p. 40-73.

7. Corrêa CMC, Dedecek RA, Roloff G. Sedimentos provenientes de estradas de uso florestal em condição de relevo ondulado a fortemente ondulado. R. Floresta. 2010; 40(1):221-234.

8. Santos CA, Sobreira FG, Coelho Neto AL. Comportamento hidrológico superficial e erodibilidade dos solos da região de Santo Antônia do Leite, Distrito de Ouro Preto - MG. R. Esc. Minas. 2002; 55(4):285-290.

9. Prieto CC. Investigação sobre implantação de loteamentos e a ocorrência de processos erosivos: voçoroca situada no Jardim Santa Edwirges em Ponta Grossa - PR [dissertação]. Ponta Grossa (PR): Universidade Estadual de Ponta Grossa; 2010. 96 p.

10. Alves RR. Monitoramento dos processos erosivos e da dinâmica hidrológica e de sedimento de uma voçoroca: estudo de caso na Fazenda do Glória na zona rural de Uberlândia - MG [dissertação]. Uberlândia (MG): Universidade Federal de Uberlândia; 2007. 104 p.

11.CPRM - Serviço Geológico do Brasil. Ação Emergencial para Delimitação de Áreas em Alto e Muito Alto Risco a Enchentes e Movimentos de Massa - Rondon do Pará, Pará. Pará: 2015. 36 p.

12. Sodré GRC, Rodrigues LLM. Comparação Entre Estimativa da Precipitação Observada Pela Técnica CMORPH e Estações Meteorológicas do INMET em Diferentes Regiões do Brasil. Revista Brasileira de Geografia Física. 2013; 6:301-307.

13. Araújo NA, Guetter AK. Validação da chuva estimada por satélite "CMORPH" na modelagem hidrológica do Alto Iguaçú. RBRH. 2007; 12(3):189-198.

14. Organização Meteorológica Mundial . Calculation of monthly and annual 30-year standard normals. Geneva, 1989. (WMO. Technical document, n. 341; WCDP, n .10).

15. Thornthwaite CW, Mather JR. The water balance. Centerton, NJ: Drexel Institute of Technology Laboratory of Climatology, 1955. 104 p. (Publications in Climatology, vol. VIII, n.1).

16.PARÁ. Coordenadoria Estadual de Defesa Civil. Banco de dados e registros de desastre: Sistema Integrado de Informações sobre Desastres - S2ID; 2015. Disponível em: s2id.mi.gov.br. Acesso em: 09 de set. de 2015. 
17. Castro JMG, Sobreira FG, Gomes RC, Gomes GJC. Proposição de procedimento preventivo de riscos geológicos em Ouro Preto - BR com base em histórico de ocorrências e sua correlação com a pluviosidade. R. Bras. Geociências. 2012; 42(1):58-66.

18. Instituto Nacional de Meteorologia - INMET. Normais Climatológicas do Brasil 1961 - 1900. Disponível em: http://www.inmet.gov.br/portal/index.php?r=clima/normaisClimatologicas. Acesso em: 19 de agosto de 2016.

19. Tatizana C, Ogura AT, Cerri LES, Rocha MCM. Análise de Correlação entre Chuvas e Escorregamentos - Serra do Mar, Município de Cubatão. In: ABGE, Congresso Brasileiro de Geologia de Engenharia, 5., 1987. São Paulo. Anais... São Paulo: ABGE, 1986 p. 225-236.

20.Delmonaco G, Ippolito F, Margottini C. The CEC Project. Meteorological Factors infl uencing slope stability and slope movement type: evaluation of hazard prone areas. In: Hydrological and Hydrogeological Risks: Proceedings of the First Review Meeting, 1., 1995. p. 259-283. 